\title{
Pemanfaatan Teknologi Dalam Mengurangi Readmission Pada Pasien Dengan Gagal Jantung: Systematic Review
}

\author{
Cicirosnita Jayadi Idu ${ }^{1}$, Josepha Mariana Tamaela ${ }^{1}$, Anggi Lukman \\ Wicaksana $^{2^{*}}$ \\ ${ }^{1}$ Program Studi Magister Keperawatan, Fakultas Kedokteran, Kesehatan \\ Masyarakat dan Keperawatan Universitas Gadjah Mada, Yogyakarta, Indonesia \\ J1. Farmako Sekip Utara, Yogyakarta 55281 \\ Email: 1 rosnitacici@ gmail.com, ${ }_{1}$ josephamaria31@gmail.com \\ ${ }^{2}$ Departemen Keperawatan Medikal Bedah, Fakultas Kedokteran, Kesehatan \\ Masyarakat dan Keperawatan Universitas Gadjah Mada, Yogyakarta, Indonesia \\ Jl. Farmako Sekip Utara, Yogyakarta 55281 \\ ${ }^{3}$ The Sleman Health Demographic and Surveillance System, Fakultas Kedokteran, \\ Kesehatan Masyarakat dan Keperawatan, Universitas Gadjah Mada, Yogyakarta \\ Email: ${ }^{2}$ anggi.l.wicaksana@ugm.ac.id \\ *Corresponding author
}

Tanggal Submisi:8 Juli 2020; Tanggal Penerimaan: 20 Februari 2021

\begin{abstract}
ABSTRAK
Gagal jantung merupakan penyakit yang membutuhkan regimen pengobatan yang lama dan kompleks. Tingginya tingkat kekambuhan pada pasien dengan gagal jantung menyebabkan kemungkinan lama hari perawatan atau kemungkinan untuk dirawat kembali (readmission) di rumah sakit. Penelitian ini bertujuan untuk menganalisis pengaruh pemanfaatan teknologi terhadap tingkat readmission pada pasien gagal jantung. Review sistematis digunakan sebagai metode dalam penelitian. Artikel diperoleh dari PubMed, ProQuest, ScienceDirect, dan EBSCO dengan kata kunci pencarian: "Management Technology", "Heart Failures", dan "Readmission". Artikel yang terbit dalam 10 tahun terkahir dan berbahasa Inggris dilakukan proses review. Selanjutnya, artikel dianalisis menggunakan analisis konten. Terdapat tiga artikel penelitian yang memenuhi kriteria dan mengindikasikan luaran penelitian. Pasien dengan gagal jantung memiliki resiko tinggi untuk dirawat inap kembali (readmission). Upaya pemanfaatan teknologi dalam menurunkan readmission dapat berupa interactive voice response system (IVRS) dengan daily self-management dan clinical monitoring, penggabungan pelatihan telepon perawatan transisi dengan telemonitoring, dan home telemonitoring. Diantara ketiga artikel tersebut bahwa interactive voice response system (IVRS) dengan daily self-management dan clinical monitoring lebih disarankan dibandingkan dua metode lainnya terhadap readmission 30 hingga 180 hari pada pasien gagal jantung. Inti dari Pemanfaatan teknologi yakni pasien gagal jantung mampu secara mandiri melakukan selfmanagement.
\end{abstract}


Sebagai upaya penurunan readmission pasien gagal jantung, maka perlunya manajemen teknologi interaktif agar pasien dapat memantau kondisinya selama perawatan di rumah.

Kata kunci: Gagal jantung, readmission, review, teknologi

ISSN 1979-7621 (Print). ISSN 2620-7761 (Online).

DOI : $10.23917 /$ jk.v14i1.11442

\begin{abstract}
Heart failure is a chronic disease, which requires complex and long medication. Patients with heart failure are at high risk of readmission and prolong of stay in hospital. This review aimed to analysis the effect of technological management on readmission among patients with heart failure. We conducted systematic review in PubMed, ProQuest, ScienceDirect, and EBSCO databases. The serach terms were "Management Technology", "Heart Failures", and "Readmission". Only published articles within last 10 years and English language were analysed using content analysis. We identified three articles met the criteria and proceeded for analysis. Patients with heart failure are in a higher risk of hospital readmission. To reduce the risk of hospital readmission, several technological approaches could be conducted, such as interactive voice response system with daily self-management and clinical monitoring, combination of translational care phone call and telemonitoring, and home telemonitoring. Among the three articles, an interactive voice response system (IVRS) with daily self-management and clinical monitoring was recommended compared to other methods of 30-180 days of reentry in heart failure patients. The core of the technological management was to enable patients in self-management on their diseases. Using a technology can assist patients with failure to reduce the admission rate and encourage them to do self-monitoring on their health states
\end{abstract}

Keywords: Heart failure, readmission, review, technology

\section{PENDAHULUAN}

Penyakit kardiovaskuler menjadi salah satu penyakit tidak menular (PTM) yang paling banyak terjadi seiring bertambahnya usia seseorang. Data WHO pada tahun 2015 menunjukan bahwa $70 \%$ kematian di dunia disebabkan oleh penyakit tidak menular (39,5 juta dari 56.4 kematian). Dari seluruh kematian akibat PTM tersebut $45 \%$ diantaranya disebabkan oleh penyakit jantung dan pembuluh darah, yaitu 17.7 juta dari 39.5 juta kematian (P2PTM Kemenkes RI, 2019). Berdasarkan hasil riset kesehatan dasar tahun 2018 prevalensi penyakit jantung menurut diagnosa dokter di Indonesia sejumlah $1.5 \%$ dan provinsi tertinggi berada di Kalimantan Utara sebanyak 2,2\% (Kementrian Kesehatan, 2018).

Penyakit jantung terbagi menjadi beberapa jenis diantaranya penyakit jantung koroner, gangguan irama jantung, penyakit jantung bawaan, gagal jantung, penyakit katup jantung. Salah satu gangguan 
kardiovaskuler yang paling banyak terjadi yakni gagal jantung yang memiliki angka mortalitas dan mobiditas yang tinggi baik di negara maju maupun di negara berkembang seperti Indonesia.

Gagal jantung adalah kumpulan gejala yang kompleks dimana seseorang pasien memiliki berbagai gejala berupa nafas pendek saat istirahat atau saat melakukan aktifitas disertai dengan kelelahan, munculnya tanda retensi cairan dilihat dengan adanya kongestif paru atau edema tungkai dan adanya bukti objektif dari gangguan struktur atau fungsi jantung saat istirahat (Siswanto et al., 2015). Dengan tanda dan gejala tersebut, gagal jantung membutuhkan regimen pengobatan yang lama dan kompleks selama periode hidup (Meng et al., 2016). Hal ini menyebabkan kemungkinan lama rawat atau tingginya kekambuhan untuk dirawat kembali di rumah sakit yang berdampak bukan hanya bagi kondisi pasien secara umum tetapi juga kondisi sosial dan ekonomi.

Untuk mengurangi lamanya masa rawat dan kekambuhan sehingga perlu readmission di rumah sakit dilakukan berbagai macam upaya dengan melibatkan pasien secara aktif dalam memanajemen diri (Athilingam et al., 2016). Upaya lainnya yang dilakukan untuk membantu memanajemen kesehatan diri pasien gagal jantung yakni dengan penerapan teknologi. Penggunaan teknologi informasi saat ini secara radikal ikut mengambil bagian dalam membantu sektor kesehatan terkait pemberian layanan kesehatan, termasuk membantu pasien dengan gagal jantung untuk memanajemen dirinya (Daniel, 2018). Sehingga diharapkan dengan penggunaan teknologi kesehatan secara maksimal dapat membantu pasien gagal jantung mengurangi resiko kekambuhan dan readmission di rumah sakit. Pemahaman terkait pemanfaatan teknologi kiranya tidak hanya dipahami oleh pasien dengan gagal jantung tetapi penting untuk tenaga kesehatan khususnya perawat untuk membantu pasien memahami dan menerapkan teknologi kesehatan sebagai bentuk pencegahan kekambuhan.

\section{METODE PENELITIAN}

\section{Strategi Pencarian}

Pencarian elektronik dilakukan secara sistematis melalui database PubMed, ProQuest, Sciencedirect, dan EBSCO. Kata bantu DAN/ATAU digunakan untuk menggabungkan kata kunci pencarian termaksud: "Management Technology", "Heart Failures", dan "Readmission".

Strategi pencarian difokuskan pada artikel yang diterbitkan dalam bahasa Inggris. Semua hasil pencarian diidentifikasi melalui judul dan abstrak terlebih dahulu. Kemudian dilakukan penyaringan dan penilaian berdasarkan pada kriteria inklusi dan eksklusi (pengecualian). Jika sesuai, maka teks yang lengkap di unduh untuk dilakukan peninjauan lebih dalam.

\section{Kriteria Inklusi dan Pengecualian}

Studi termaksud artikel peer review penelitian primer yang menyelidiki efek penerapan manajemen teknologi terhadap readmission pasien gagal jantung yang menjalani rawat jalan. Artikel terbit di Jurnal Internasional minimal 10 tahun terakhir dan menggunakan bahasa Inggris. Design penelitian menggunakan Randomized Controlled Trial (RCT) dan Clinical Trial (CT). Artikel dikeluarkan dalam proses review apabila tidak dapat di akses full-text oleh peneliti.

\section{HASIL DAN PEMBAHASAN}

Seratus dua puluh enam artikel muncul dalam proses pencarian di database, dan terdapat 47 duplikasi yang dihapus. Semua artikel di-screening berdasarkan judul dan abstrak dan didapati 15 artikel yang sesuai, sementara 64 artikel dieksklusikan karena tidak sesuai dengan tujuan penelitian. Selanjutnya dilakukan penilaian berdasarkan kriteria inklusi, terdapat 12 artikel yang dieksklusi karena tidak sesuai dengan alasan artikel tidak sesuai tujuan, tidak menggunakan desain RCT atau CT, dan terbitan lebih dari 10 tahun. Sehingga 3 artikel dilakukan proses ekstraksi dan analisa 
lebih lanjut.

Artikel yang memenuhi egibilitas dilakukan penilaian dengan menggunakan instrument Critical Appraisal Skill Programe (CASP) (CASP UK, 2017). Ketiga artikel telah dinilai dan layak untuk dilakukan proses review. Seluruh proses pencarian sistematis dilakukan dengan menggunakan panduan Preferred Reporting Item for Sistematic Reviews and Meta-Analyses (PRISMA) seperti pada Gambar 1 (Moher, et al, 2009; Rosyida et al, 2018).

Data artikel yang ditampilkan berupa penulis/tahun publikasi/negara asal, tujuan, sampel, metode pengumpulan data, intervensi, dan hasil penelitian (Tabel 1). Data terkait pemanfaatan teknologi dispesifikan pada jenis, starategi, dan outcome yang dihasilkan.

Ketiga artikel mengulas manfaat penerapan manajemen teknologi pada readmission pasien gagal jantung. Pencegahan readmission atau rawat inap ulang pasien gagal jantung dengan cara mengidentifikasi pasien risiko tinggi di awal sebelum masuk ke bangsal perawatan, agar dapat meminimalkan risiko yang dapat dimodifikasi dan membuat rencana pemantauan perawatan paska-akut (Cox et al., 2018) atau menyiapkan intervensi yang matang mulai dari sebelum perawatan sampai paska pemulangannya (Ove et al., 2020). Selain itu penting dalam melakukan manajemen gagal jantung melibatkan pasien secara aktif dalam tugas manajemen diri yang kompleks untuk menjaga stabilitas fisiologis. Pasien juga diharapkan menggunakan pengambilan keputusan yang baik dalam menanggapi gejala yang timbul saat pasien berada di rumah (Athilingam et al., 2016).

Salah satu upaya untuk menekan tingkat readmission bagi pasien dengan gagal jantung yakni manajemen mandiri dan melibatkan teknologi informasi. Penggunaan teknologi informasi kesehatan akan secara radikal mengubah sektor layanan kesehatan dengan meningkatkan efisiensi, mengurangi pengeluaran dan meningkatkan kualitas pemberian pelayanan (Athilingam et al.,
2016; Daniel, 2018). Hal ini sesuai dengan hasil penelitian yang disebutkan pada ketiga artikel terkait penggunaan manajemen teknologi pada pasien gagal jantung.

Upaya pemanfaatan teknologi mandiri untuk membantu pasien dengan gagal jantung merupakan solusi yang menjanjikan untuk mengurangi tingkat rawat inap (readmission) dan kematian (Kotooka et al, 2018). Salah satunya telemonitoring yang sudah diterapkan di Jepang meskipun belum sepenuhnya dapat diinvestigasi. Tetapi penggunaan sistem telemonitoring dari rumah yang lebih terintegrasi menekankan aspek komunikasi serta dapat memantau gejala secara mandiri sehingga mengurangi tingkat kekambuhan (Kotooka et al, 2018).

Hasil sistematis review oleh Daniel (2018), bahwa lembaga-lembaga dengan skor Health Information Technology (HIT) tertinggi menyadari dampak dari teknologi terhadap dukungan keputusan klinis, kontinuitas dokumentasi perawatan dan kepulangan klinis, serta ringkasan kesusahan dokumen perawatan menunjukkan pengurangan yang cukup dan signifikan secara statistik dalam readmission 30 hari tanpa efek lama tinggal. Manajemen teknologi interaktif merupakan bagian dari program berbasis rumah dengan alat bantu perangkat lunak. Penerapan program perangkat lunak dapat menggunakan e-mail, telemonitoring, mobile aplikasi berbasis ponsel, kunjungan rumah, dan informasi melalui interview telepon (Inglish et al, 2011).

Ketiga artikel menggunakan media telepon untuk melakukan monitoring rawat jalan pasien gagal jantung (Austin et al., 2012; Black et al., 2014; Kotooka et al., 2018). Austin et al. (2012) mengungkapkan bahwa banyak pasien gagal jantung yang kesulitan dalam menggunakan atau akses computer. Sehingga pengiriman teks pesan melalui telpon digunakan sebagai alternatif. Begitupun halnya dengan penelitian Black et al. (2014) yang mengkombinasikan adaptasi perawatan melalui program telepon transisi dengan telemonitoring pada readmission pasien gagal jantung. Selain itu, studi 
Kotooka et al. (2018) terkait penggunaan home telemonitoring menjadi lebih penting untuk perawatan pasien di rumah.

Berdasarkan ketiga artikel tersebut masing-masing memiliki manfaat yang baik dalam mengurangi readmission pasien gagal jantung. Namun, pada metode interactive voice response system (IVRS) dengan daily self-management dan clinical monitoring lebih disarankan untuk digunakan. Hal ini didukung oleh hasil uji statistik fisher exact 2-tailed yaitu $\mathrm{p}$-value $=.047$

Prosedur pelaksanaan media telepon yaitu dimulai dengan sambutan dari sistem rumah sakit. Pasien kemudian diminta untuk menekan kunci telepon sebagai penanda jika mereka ingin menerima pesan segera atau lambat. Namun, jika telepon tidak dijawab, maka sistem akan menelpon kembali satu jam kemudian. Sambutan ini sekaligus diikuti oleh pesan pendidikan selama 60 detik (Austin et al, 2012). Prosedur lainnya berdasarkan penelitian, yaitu pasien akan menerima serangkaian sembilan panggilan telepon pembinaan kesehatan yang telah terjadwal selama lebih dari enam bulan dari perawat di call center (Black et al.,2014). Pendidikan pra-pemulangan yang diberikan juga mencakup demonstrasi bagaimana cara menggunakan peralatan home telemonitoring jarak jauh dan penjelasan mengapa penting untuk memantau parameter fisiologis pasien seperti berat badan, tekanan darah, dan denyut nadi (Kotooka et al, 2018). 
C.J Idu, J.M Tamaela \& A.L Wicaksana / Jurnal Kesehatan 14 (1) 2021, 48-58

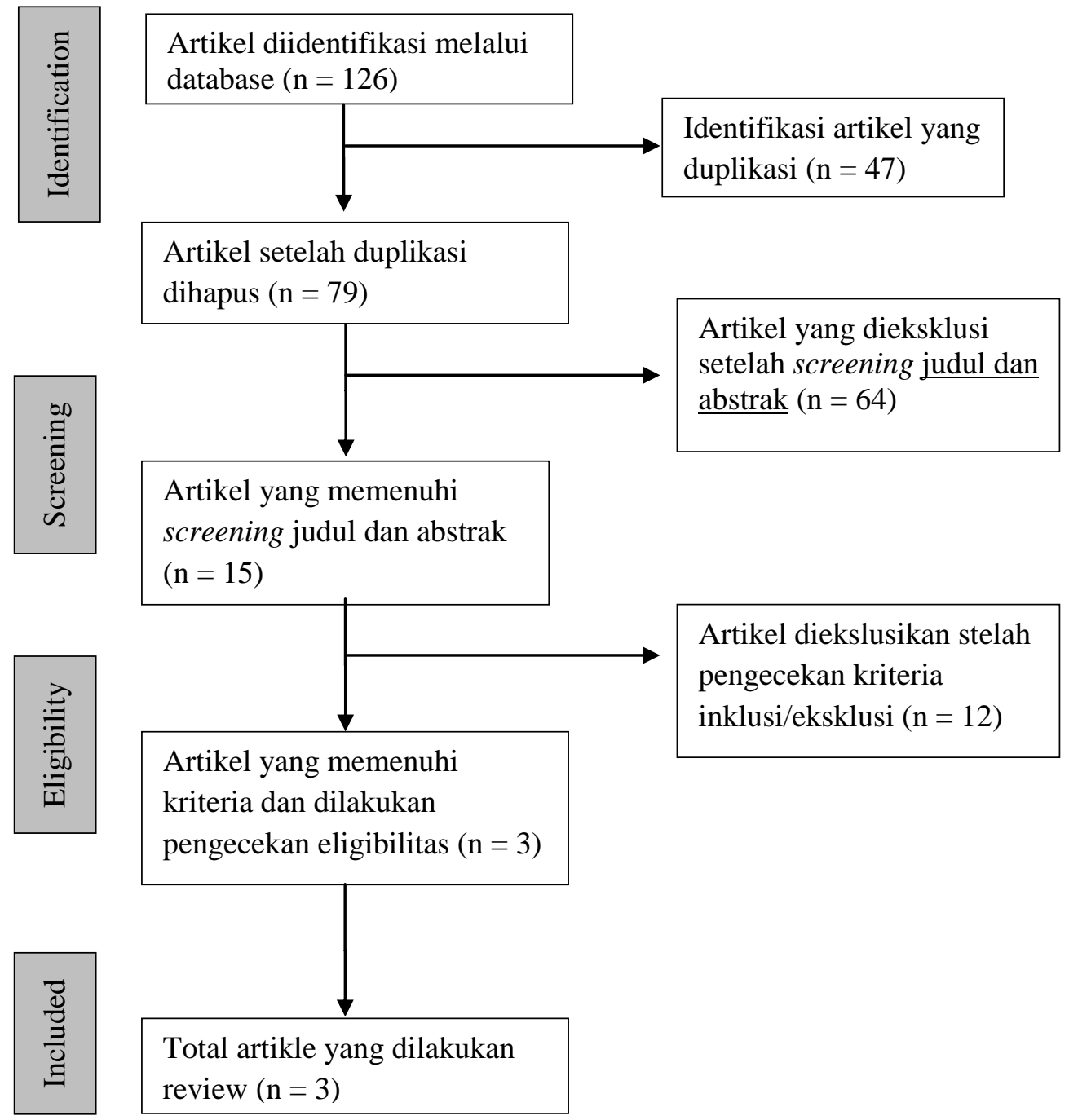

Gambar 1. Diagram PRISMA Proses Peninjauan Sistematis 
Tabel 1. Ekstraksi Data dari Artikel yang memenuhi Kriteria

\begin{tabular}{|c|c|c|c|c|c|c|c|}
\hline No & $\begin{array}{c}\text { Penulis/ } \\
\text { Tahun/ } \\
\text { Negara }\end{array}$ & Judul & Tujuan & Sampel & Metode & Intervensi & Hasil Penelitian \\
\hline 1 & $\begin{array}{l}\text { Austin et al } \\
\text { (2012), US }\end{array}$ & $\begin{array}{l}\text { Extending the } \\
\text { continum of } \\
\text { care in } \\
\text { congestive } \\
\text { heart failure }\end{array}$ & $\begin{array}{l}\text { Untuk menentukan } \\
\text { interactive voice response } \\
\text { system (IVRS) dengan } \\
\text { pengelolaan diri harian } \\
\text { dan pemantauan klinis } \\
\text { selama } 30 \text { hari yang } \\
\text { diterima oleh pasien gagal } \\
\text { jantung kongestif dan } \\
\text { mengurangi readmission. }\end{array}$ & $\begin{array}{l}60 \text { pasien } \\
\text { gagal } \\
\text { jantung }\end{array}$ & $\mathrm{CT}$ & $\begin{array}{l}\text { IVRS yaitu pesan suara } \\
\text { melalui Mp3 player untuk program } \\
\text { rawat jalan. } \\
\text { Pasien menerima pesan IVRS setiap } \\
\text { hari selama } 30 \text { hari terkait pendidikan } \\
\text { pengelolaan mandiri berdasarkan gejala } \\
\text { yang dilaporkan sendiri. } \\
\text { Sedangkan } 4 \text { elemen dasar yang } \\
\text { disebutkan di setiap pesan: kepatuhan } \\
\text { minum obat, batasan asupan garam, } \\
\text { pentingnya timbang BB setiap hari, dan } \\
\text { kebutuhan untuk menguhungi dokter } \\
\text { untuk penambahan BB } 2 \text { libra }(\sim 0.907 \\
\text { Kg) atau lebih besar dalam } 24 \text { jam. }\end{array}$ & $\begin{array}{l}\text { Mayoritas pengurangan } \\
>50 \% \text { terkait tingkat } \\
\text { readmission diwujudkan } \\
\text { dalam } 30 \text { hari. Artinya } \\
\text { bahwa manajemen diri IVRS } \\
\text { adapat menjadi teknologi } \\
\text { yang efektif untuk } \\
\text { mengurangi penerimaan } \\
\text { kembali CHF. Dibuktikan } \\
\text { dengan hasil analisis uji } \\
\text { fisher exact 2-tailed yaitu p- } \\
\text { avalue }=.047\end{array}$ \\
\hline$\overline{2}$ & $\begin{array}{l}\text { Black et al } \\
\text { (2014), US }\end{array}$ & $\begin{array}{l}\text { A remote } \\
\text { monitoring and } \\
\text { telephone nurse } \\
\text { coaching } \\
\text { intervention to } \\
\text { reduce } \\
\text { readmissions } \\
\text { among patients } \\
\text { with heart } \\
\text { failure: } \text { studi } \\
\text { protocol for the } \\
\text { Better }\end{array}$ & $\begin{array}{l}\text { Untuk } \\
\text { mengevaluasi efektivitas } \\
\text { intervensi perawatan } \\
\text { transisi yang mencangkup } \\
\text { pendidikan pra } \\
\text { kepulangan tentang gagal } \\
\text { jantung dan pelatihan } \\
\text { post- dischange telephone } \\
\text { nurse dikombinasikan } \\
\text { dengan home } \\
\text { telemonitoring dari gejala } \\
\text { peningkatan tekanan }\end{array}$ & $\begin{array}{l}1500 \\
\text { pasien usia } \\
\text { diatas } 50 \\
\text { tahun }\end{array}$ & $\mathrm{CT}$ & $\begin{array}{l}\text { Intervensi berupa } \\
\text { penggabungan pelatihan via telepon } \\
\text { perawatan transisi dengan } \\
\text { telemonitoring. } \\
\text { Pasien dalam kelompok intervensi akan } \\
\text { menerima edukasi intensif } \\
\text { menggunakan metode 'teach-back' dan } \\
\text { menerima instruksi dalam penggunaan } \\
\text { peralatan telemonitoring. }\end{array}$ & $\begin{array}{l}\text { Hasil utama adalah } \\
\text { readmission untuk alasan apa } \\
\text { pun dalam } 180 \text { hari. } \\
\text { Hasil sekunder termasuk } \\
\text { readmission } 30 \text { hari, } \\
\text { kematian, hari sakit, } \\
\text { kunjungan gawat darurat, } \\
\text { biaya rumah sakit, dan } \\
\text { kualitas hidup terkait } \\
\text { kesehatan. Hasil uji statistik } \\
\text { yang digunakan } \\
\text { menggunakan analisis }\end{array}$ \\
\hline
\end{tabular}


Effectiveness darah, nadi, dalam

After mengurangi semua

Transition- penyebab readmission

Heart Failure rumah sakit selama 180

(BEAT- HF) hari untuk lansia.

randomized

controlled trial akan menerima serangkaian sembilan

panggilan telepon pembinaan

regresi multivariat tetapi

hasil statistik tidak

kesehatan terjadwal lebih dari 6 bulan dicantumkan secara rinci dari perawat yang berlokasi di call

center. Perawat juga akan memanggil

pasien dan dokter pasien sebagai

tanggapan atas peringatan yang

dihasilkan oleh sistem telemonitoring,

berdasarkan parameter yang telah

ditentukan.

3 Kotooka et The first al (2018),

Jepang

multicenter,

Untuk melihat keefektifan 181 pasien

(kelompok

monitoring

$=90$;

controlled trial jantung

of home

telemonitoring

for Japanese

kelompok

perawatan

patients with

biasa $=91)$

heart failure:

home

telemonitoring

study for

patients with

heart failure

(HOMES-HF) dari skala elektronik dengan meter "penerima," yang menerima data
Sistem telemonitoring rumah terdiri komposisi tubuh, sphygmomanometer dan perangkat yang disebut fisiologis yang diperoleh, termasuk tekanan darah, denyut nadi, berat badan, dan komposisi tubuh, secara nirkabel dan mentransmisikan data ke server web pusat melalui internet dan didistribusikan kepada para peserta yang ditugaskan ke grup telemonitoringmenekankan komunikasi ketika mereka dipulangkan dari rumah serta dapat memantau gejala sakit. Para pasien ditunjukkan bagaimana menggunakan perangkat pemantauan, dan mereka didorong untuk mengukur sendiri berat badan dan tekanan darah mereka setidaknya sekali sehari pada waktu yang hampir bersamaan
Telemonitoring untuk pasien Jepang dengan gagal jantung yang ditimbulkan belum dapat sepenuhnya diinvestigasi antara kelompok monitoring dan kelompok perawatan Tetapi penggunaan sistem telemonitoring rumah yang lebih terintegrasi kekambuhan sehingga mengurangi tingkat kekambuhan. . Analisis uji statistik menunjukan $\mathrm{p}=$ 0.572

Keterangan: BB: berat badan, CT: clinical trial, IVRS: interactive voice response system, Kg: kilogram, RCT: randomized controlled trial, US: United States. 
Ketiga artikel mengulas hal yang sama terkait manajemen teknologi. Kontennya berisi pendidikan pasien terkait elemen inti self-management pasien gagal jantung (Austin et al, 2012). Perawat menggunakan buklet "Peduli Jantungmu: Hidup Sehat dengan Gagal Jantung", dan dikembangkan untuk pasien dengan kesadaran yang rendah terkait kesehatan. Topik yang dibahas dalam buklet ini mencakup penjelasan tentang gagal jantung, kepatuhan pengobatan, penghindaran asupan garam, memantau cairan, teknik berolahraga pada pasien gagal jantung, pemeriksaan harian berat, dan edema, serta kapan harus menguhungi tim perawatan gagal jantung (DeWalt et al, 2006).

Pendekatan 'teach-back' digunakan perawat untuk memastikan pemahaman pasien. Anggota keluarga atau pengasuh lainnya dilibatkan dalam sesi pengajaran jika bersedia dan ingin berpartisipasi. Perawat juga akan memanggil pasien dan dokter pasien sebagai tanggapan atas peringatan yang dihasilkan oleh sistem telemonitoring, berdasarkan parameter yang telah ditentukan (Black et al, 2014).

\section{KESIMPULAN}

Peningkatan jumlah pasien gagal jantung berdampak pula pada jumlah pasien rawat inap di rumah sakit. Sebagai upaya penurunan readmission pasien gagal jantung, maka perlunya manajemen teknologi interaktif untuk nantinya memantau kondisi pasien selama perawatan di rumah. Berbagai jenis teknologi interaktif yaitu interactive voice response system (IVRS) dengan daily self-management dan clinical monitoring, penggabungan pelatihan telepon perawatan transisi dengan telemonitoring, dan home telemonitoring. Hasil ketiganya menunjukkan bahwa adanya pengaruh pada readmission 30 hari hingga 180 hari, akan tetapi interactive voice response system (IVRS) dengan daily self-management dan clinical monitoring lebih disarankan untuk digunakan. Selain itu pemanfaatan teknologi bermanfaat dalam memantau gejala secara mandiri sehingga mengurangi tingkat kekambuhan pasien. Hasil review ini memberikan gambaran baru terkait pengunaan teknologi untuk mengurangi readmission pasien gagal jantung yang belum banyak dibahas.

\section{UCAPAN TERIMAKASIH}

Peneliti mengapresiasi setinggitingginya kepada Universitas Gadjah Mada yang telah menfasilitasi dan memberikan akses untuk melaksanakan review ini.

\section{DAFTAR PUSTAKA}

Athilingam, P., Labrador, M.A., Remo, E.F.J., Mack, L., Bianca, A., Juan, S., \& Elliott, A. F. (2016). Features and Usability Assessment of A Patient-centered Mobile Application (HeartMapp) for Self-management of Heart Failure. Applied Nursing Research. 32:156-163.

Austin, L.S., Landis, C.O., \& Hanger, K.H. (2012). Extending the Continuum of Care in Congestive Heart Failure: An Interactive Technology Self-Management Solution. The Journal of Nursing Administration. 42(9):442-446.

Black, J.T., Romano, P.S., Sadeghi, B., Auerbach, A.D., Ganiats, T.G., Greenfield, S., Kaplan, S.H., Ong, M.K., \& The BEAT-HT Research Gorup. (2014). A Remote Monitoring and Telephone Nurse Coaching Intervention to Reduce Readmissions among Patients with Heart Failure: Study Protocol for the Better Effectiveness after Transition-Heart Failure (BEAT-HF) Randomized controlled trials. The Journal 
BioMed Central. 15:24.

CASP UK. (2017). Critical Appraisal Skills Programme (CASP). Qualitative Research Checklist. 31(13): 449.

Cox, Z.L., Lai, P., Lewis, C.M., Lindenfeld, J., Collins, S.P., \& Lenihan, D.J. (2018). Customizing National Models for A Medical Center's Population to Rapidly Identify Patients at High Risk of 30-day All-cause Hospital Readmission Following A Heart Failure Hospitalization. Heart \& Lung. 47(4): 290-296.

Daniel, O.U. (2018). Effects of Health Information Technology and Health Information Exchanges on Readmissions and Length of Stay. Health Policy and Technology. 7(3): 281-286.

DeWalt, D.A., Malone, R.M., Bryant, M.E., Kosnar, M.C., Corr, K.E., Rothman, R.L., Sueta, C.A., \& Pignone, M.P. (2006). A Haert Failures Self-Management Program for Patients of all Literacy Level: A Randomized Controlled Trials. BMC Health Serv Res. $6(30)$.

Inglis, S.C.,Clark, R.A., McAlister F.A., et al. (2011). Which Components of Heart Failure Programmes Are Effective? A Systematis Review and Meta-Analysis. European Journal of Heart Failure. 13(9):1028-1040.

Kementrian Kesehatan. (2018). Hasil Utama Riskesdas 2018 Kementerian Kesehatan Ri Badan Penelitian Dan Pengembangan Kesehatan. Tersedia dari http://www.kesmas.kemkes.go.id/assets/upload/dir_519d41d8cd98f00/files/Hasilriskesdas-2018_1274.pdf.

Kotooka, N., Kitakaze, M., Nagashima, K., Asaka, M., \& Kinugasa, Y. (2018). The First Multicenter, Randomized, Controlled Trial of Home Telemonitoring for Japanese Patients with Heart Failure: Home Telemonitoring Study for Patients with Heart Failure (HOMES-HF). Heart Vessels. 33:866-876.

Meng, K., Musekamp, G., Schuler, M., Seekatz, B., Glatz, J., Karger, G., et al. (2016). Patient Education and Counseling The Impact of A Self-Management Patient Education Program for Patients with Chronic Heart Failure Undergoing Inpatient Cardiac Rehabilitation. Patient Education and Counseling. 99(7): 1190-1197.

Moher, D., Liberati, A., Tetzlaff, J., Altman, D.G., The PRISMA Group (2009). Preferred Reporting Items for Systematic Review and Meta-Analyses: The PRISMA Statement. Plos Medicine. 6(7):e1000097.

Ove, S., Moons, P., Sandvik, L., Leegaard, M., Solheim, S., Tønnessen, T., \& Lie, I. (2020). Impact of Telephone Follow-up and 24/7 Hotline on 30-day Readmission Rates Following Aortic Valve Replacement - A Randomized Controlled Trial. International Journal of Cardiology. 300:66-72.

P2PTM Kemenkes RI. (2019). Hari Jantung Sedunia (HJS) Tahun 2019: Jantung Sehat, SDM 
C.J Idu, J.M Tamaela \& A.L Wicaksana / Jurnal Kesehatan 14 (1) 2021, 48-58

Unggul. Tersedia dari http://p2ptm.kemkes.go.id/kegiatan-p2ptm/pusat-/hari-jantungsedunia-hjs-tahun-2019-jantung-sehat-sdm-unggul.

Rosyida, R.W., Sa'bani, N.A., Ruly, A.S., Putra, M.G.A., \& Wicaksana, A.L. (2018). Pengaruh Program Manajemen Perawatan terhadap Penurunan Tingkat Readmisi Pada Pasien Penyakit Paru Obstruksi Kronik. Jurnal Kesehatan. 11(2): 75-84.

Siswanto, B.B., Hersunarti, N., Erwinanto, Barack, R., Pratikto, R.S., Nauli, S.E., \& Lubis, A. (2015). Pedoman tatalaksana gagal jantung (Edisi Pertama). Jakarta: Indonesian Heart Association. 